\title{
Perennial wild relatives of chickpea as potential sources of resistance to Helicoverpa armigera
}

\author{
H.C. Sharma ${ }^{1}{ }^{*}$, M.P. Bhagwat ${ }^{1}$, G. Pampapathy ${ }^{1}$, J.P. Sharma ${ }^{2}$ and T.J. Ridsdill-Smith ${ }^{3}$ \\ ${ }^{1}$ International Crops Research Institute for the Semi-Arid Tropics (ICRISAT), Patancheru 502 324, Andhra \\ Pradesh, India; ${ }^{2}$ Dr YS Parmar University of Horticulture \& Forestry, Regional Research Station, Seobagh, \\ Kullu, Himachal Pradesh, India; ${ }^{3}$ Commonwealth Scientific and Industrial Research Organization (CSIRO), \\ Entomology, Private Bag 5, Wembley 6913, Western Australia, Australia; *Author for correspondence \\ (e-mail: h.sharma@cgiar.org; phone: +91-40-23296161; fax: +91-40-23296182)
}

Received 11 February 2004; accepted in revised form 23 July 2004

Key words: Cicer spp. Perennial wild relatives of chickpea, Helicoverpa armigera, Host plant resistance, Pod borer

\begin{abstract}
The legume pod borer, Helicoverpa armigera (Hübn.), is one of the major constraints to chickpea production, and host plant resistance is an important component for the management of this pest. The levels of resistance in the cultivated chickpea are low to moderate, and therefore, we evaluated 17 accessions of perennial Cicer along with three cultivated chickpea genotypes for resistance to $H$. armigera. There was a significant reduction in both leaf feeding and larval weights when the larvae were fed on the leaves of Cicer microphyllum Benth. accessions ICC 17146, ICC 17236, ICC 17240, and ICC 17248. Relative resistance index based on leaf feeding, larval survival, and larval weight indicated that $C$. microphyllum accessions ICC 17146, ICC 17236, ICC 17234, ICC 17240, ICC 17243, and ICC 17248 were highly resistant to $H$. armigera. Under natural infestation, accessions belonging to C. microphyllum, C. canariense Santos Guerra et Lewis, and C. macracanthum M. Pop suffered a damage rating of $<2.0$ compared to 4.0 in $C$. judaicum Boiss. accession ICC 17148 (annual species) and 8.5-9.0 in the cultivated chickpeas ( $1=<10 \%$ leaf area damaged, and, $9=>80 \%$ leaf area damaged). There was considerable diversity in the accessions belonging to perennial wild species of chickpea, and these can be exploited to increase the levels and diversify the basis of resistance to $H$. armigera in the cultivated chickpea.
\end{abstract}

\section{Introduction}

Chickpea (Cicer arietinum L.) is one of the major grain legumes in Asia, and parts of East and North Africa, and Mediterranean Europe. In recent years, it has gained importance in Australia, Canada, and the USA. Chickpea yields have remained stagnant for the past 2-3 decades, due largely to biotic and abiotic stress factors, of which pod borer, Helicoverpa armigera (Hübn.), Fusarium wilt, Aschochyta blight, Botrytis gray mold, and low temperatures are the most important. Helicoverpa armigera has been estimated to cause more than US\$2 billion loss to field crops in the semiarid tropics, despite $\$ 500$ million worth of pesticides applied to control this pest (Sharma 2001). In chickpea, it causes $\$ 325$ million loss annually (ICRISAT 1992). Intensification of agriculture has exacerbated the $H$. armigera problem, and farmers are resorting to frequent use of toxic insecticides. 
Due to widespread use of insecticides to control this pest, particularly on cotton and other high value vegetables and grain legumes, it has developed considerable levels of resistance to conventional insecticides (Armes et al. 1996; Kranthi et al. 2002). For pest problems as intractable as $H$. armigera, the presumption is that no single tactic in itself will suffice to contain this pest.

It has long been recognized that host plant resistance would be one of the most effective management options, but thus far, the levels of resistance in the available germplasm have been found to be low to moderate (Lateef 1985; Lateef and Sachan 1990; Sharma 2001). Development of cultivars with high levels of resistance to this pest would certainly provide an effective complementary approach in integrated pest management to minimize the extent of losses due to this pest. Wild relatives of crops are useful source of genes for resistance to biotic and abiotic stress factors (Stalker 1980; Muehlbauer 1987). The genus Cicer comprises 43 species, of which 34 are wild perennial, 8 wild annual and 1 annual cultivated species. All the species are diploid $(2 n=16)$, and are self-pollinated (Ladizinsky and Adler 1976; Singh and Ocampo 1993, 1997). Cicer songaricum and C. microphyllum Benth. are the two wild species that occur in India, in addition to the cultivated species, $C$. arietinum. These wild species are confined to the dry temperate regions of Ladakh, and Lahaul and Spiti Valleys in the Himalayas. Cicer microphyllum has a high seed protein content (nearly 24-25\%) (Chandel 1984), and it is used for feeding horses and the yak by the local people. We evaluated a number of accessions of perennial wild relatives of chickpea for resistance to $H$. armigera under greenhouse and field conditions, as no such information was available to date.

\section{Materials and methods}

Interactions of perennial wild relatives of chickpea with $\mathrm{H}$. armigera under no-choice conditions (detached leaf assay)

Seventeen accessions belonging to Cicer microphyllum Benth., 1 to $C$. pungens Boiss., and 1 to C. canariense Santos Guerra et Lewis along with three cultivated chickpea genotypes (ICC $506-$ moderately resistant check, ICCC 37 - susceptible check, and Annigeri - commercial landrace cultivar) were evaluated for resistance to $H$. armigera at the International Crops Research Institute for the Semi-Arid Tropics (ICRISAT), Patancheru, Andhra Pradesh, India. The plants were raised in the greenhouse in plastic pots (30 $\mathrm{cm}$ diameter, $30 \mathrm{~cm}$ deep). The pots were filled with a potting mixture of black soil (Vertisol), sand, and farmyard manure (2:1:1). The seeds were scarified, soaked in water for $24 \mathrm{~h}$, and treated with ethrel (at $2 \mathrm{~mL}$ per $1000 \mathrm{~mL}$ ) to break dormancy. The seeds were collected from various locations about 15-20 years ago. The seeds were treated with thiram (at $2 \mathrm{~g}$ per $\mathrm{kg}$ ) and placed in a Petri dish containing agar-agar $(2 \%)$ for germination. After germination, the plants were transplanted into the soil and watered immediately. One seedling was transplanted in each pot, and there were five plants for each accession. The plants were watered as needed. The greenhouse was cooled by desert coolers to maintain the temperature at $28 \pm 5{ }^{\circ} \mathrm{C}$, and relative humidity $>65 \%$. Additional lighting was provided (14 h photoperiod) to induce flowering in the perennial species, which was unsuccessful.

Terminal branches (2-3 fully expanded leaves and a bud) of chickpea seedlings at 60 days after seedling emergence were bio-assayed for resistance to $H$. armigera using a modified version of the detached leaf assay for transgenic cotton (Olsen and Daly 2000). The chickpea branches were cut with scissors, and immediately planted in a slanting manner into $3 \%$ agar-agar medium containing $0.25 \%$ methyl $p$-hydroxy benzoate (to inhibit fungal growth in the medium) in a $250 \mathrm{~mL}$ plastic cup. There were five replications for each accession, in a completely randomized design. Ten neonate larvae of $H$. armigera raised in the laboratory (Sharma et al. 2001) were released on the chickpea leaves. All the larvae were of similar weight and size as they were released on the test material immediately after hatching from the eggs. A filter paper $(9 \mathrm{~cm}$ diameter) soaked in $2 \mathrm{~mL}$ water was stuck to the underside of the lid, and the plastic cups were covered immediately. The cups were kept in the laboratory $\left(27 \pm 2{ }^{\circ} \mathrm{C}\right.$, and $45-$ $65 \% \mathrm{RH})$. Observations were recorded 5 days after initiating the experiment. First, the plants were rated for leaf feeding $(1=<10 \%$ leaf area damaged, and $9=>80 \%$ leaf area damaged) (Sharma et al. 2002). The number of larvae surviving after 5 days were recorded, and placed in 
$25 \mathrm{~mL}$ plastic cups. The weights of larvae were recorded $4 \mathrm{~h}$ after separating them from the food. The data were expressed as percentage larval survival, and mean weight of the larvae. Data on leaf damage rating, larval survival, and larval weights were used to compute resistance index as follows.

Resistance index $=$ Leaf damage rating $\times$ larval weight/(100 - percentage larval survival).

Relative susceptibility of perennial wild relatives of chickpea to $\mathrm{H}$. armigera under multi-choice field conditions

To study the reaction of perennial wild relatives of chickpea for their relative resistance or susceptibility to $H$. armigera, 11 accessions belonging to Cicer microphyllum, 1 to $C$. pungens, 1 to C. canariense, and 1 to C. macracanthum M. Pop. along with 1 annual wild relative, $C$. judaicum Boiss. (as a resistant check) and three cultivated chickpea genotypes (ICC 506 - moderately resistant check, ICCC 37 - susceptible check, and Annigeri - commercial landrace cultivar) were evaluated for $H$. armigera resistance under multichoice conditions in the field. The seeds were sown during the 1st week of April 2003 at Kothi, near Manali (2500 $\mathrm{m}$ above mean sea level) under temperate conditions (near the native area of the perennial species). The wild relatives of chickpea, particularly C. microphyllum, grow in the wild in the adjoining valleys of Lahaul and Spiti in Himachal Pradesh, India. The wild species in this region emerge from the soil in April when the snow melts, flower in July, and mature by September before the onset of the winter season. Therefore, it was thought that these accessions of perennial wild relatives of chickpea might flower at this location, and also allow their evaluation near the area of natural distribution. The seeds were sprouted in agar-agar, and transplanted into soil in a cardboard cup ( $200 \mathrm{~mL}$ capacity). The seedlings that established in the cardboard cups were then transplanted into the soil at 1 week after transplanting into the cups. The seedlings were planted in a $1 \mathrm{~m}$ row (5 seedlings in each row), and the rows were spaced $50 \mathrm{~cm}$ apart. There were two replications in a randomized complete block design. In mid-July, the material was evaluated for leaf damage by $H$. armigera on a $1-9$ rating scale $(1=<10 \%$ leaf area da- maged, and, $9=>80 \%$ leaf area damaged), and the data were subjected to analysis of variance. To observe the growth and flowering behaviour of the wild relatives in their natural habitat, we also surveyed the Lahaul valley across Rohtang Pass ( $>4000 \mathrm{~m}$ above mean sea level) for the wild relatives, particularly, C. microphyllum.

\section{Statistical analysis}

Data were subjected to analysis of variance using GENSTAT release 5.0. The significance of differences between the treatments was measured by $F$-test at $p 0.05$, while the treatment means were compared using the least significant difference (LSD) at $p 0.05$. Data on leaf damage rating, larval survival, and larval weights were subjected to similarity matrix and Principal Component analysis to assess the diversity for resistance to $H$. armigera in perennial accessions of the wild relatives of chickpea.

\section{Results}

Interactions of perennial wild relatives of chickpea with $\mathrm{H}$. armigera under no-choice conditions (detached leaf assay)

The leaf feeding damage rating on the wild species ranged from 2.0 in ICC 17236 (C. microphyllum) to 7.3 in ICC 17243 (C. microphyllum) as compared to 7.2 in ICCC 37 (C. arietinum - the susceptible check), and 4.8 in ICC 506 (C. arietinum - moderately resistant) (Table 1). Some of the accessions belonging to $C$. canariense and $C$. microphyllum showed resistance (DR 2.0-3.7) to leaf feeding by the neonate larvae of $H$. armigera. Larval survival ranged from $62 \%$ in ICC 17248 (C. microphyllum) to $94 \%$ in ICC 17230 (C. microphyllum) as compared to $86-94 \%$ survival on cultivated chickpea. Accessions ICC 17244, ICC 17247, ICC 17248, and ICC 17249 (C. microphyllum) showed <74\% larval survival compared to $94 \%$ larval survival on ICC 506 (C. arietinum). Mean larval weights after 5 days of feeding on the detached leaves ranged from 0.769 to $2.321 \mathrm{mg}$ on C. microphyllum, $1.985 \mathrm{mg}$ on $C$. canariense, and $2.444 \mathrm{mg}$ on C. pungens as compared to $4.686 \mathrm{mg}$ on ICC $506-$ 
Table 1. Evaluation of perennial wild relatives of chickpea for resistance to Helicoverpa armigera under no-choice conditions in the greenhouse (detached leaf assay) (ICRISAT, Patancheru 2003).

\begin{tabular}{|c|c|c|c|c|c|}
\hline Accession & Species & Damage rating* & Larval survival (\%) & Larval weight $(\mathrm{mg})$ & Resistance index \\
\hline ICC 17138 & Cicer pungens Boiss. & 7.0 & 90.0 & 2.444 & 1.71 \\
\hline ICC 17202 & Cicer canariense Santos Guerra et Lewis & 3.7 & 90.0 & 1.985 & 0.73 \\
\hline ICC 17146 & Cicer microphyllum Benth. & 3.2 & 85.8 & 0.999 & 0.22 \\
\hline ICC 17230 & Cicer microphyllum Benth. & 3.5 & 94.0 & 1.787 & 1.04 \\
\hline ICC 17234 & Cicer microphyllum Benth. & 4.8 & 82.0 & 1.456 & 0.39 \\
\hline ICC 17235 & Cicer microphyllum Benth. & 4.3 & 78.0 & 1.860 & 0.36 \\
\hline ICC 17236 & Cicer microphyllum Benth. & 2.0 & 85.2 & 0.769 & 0.10 \\
\hline ICC 17237 & Cicer microphyllum Benth. & 6.0 & 86.0 & 2.321 & 0.99 \\
\hline ICC 17238 & Cicer microphyllum Benth. & 5.4 & 83.6 & 2.149 & 0.71 \\
\hline ICC 17240 & Cicer microphyllum Benth. & 3.3 & 86.0 & 1.474 & 0.35 \\
\hline ICC 17242 & Cicer microphyllum Benth. & 7.0 & 86.0 & 2.280 & 1.14 \\
\hline ICC 17243 & Cicer microphyllum Benth. & 7.3 & 82.0 & 1.286 & 0.52 \\
\hline ICC 17244 & Cicer microphyllum Benth. & 3.6 & 74.0 & 2.143 & 0.30 \\
\hline ICC 17245 & Cicer microphyllum Benth. & 5.2 & 82.0 & 1.554 & 0.45 \\
\hline ICC 17247 & Cicer microphyllum Benth. & 3.7 & 72.0 & 2.162 & 0.29 \\
\hline ICC 17248 & Cicer microphyllum Benth. & 2.4 & 62.0 & 1.357 & 0.09 \\
\hline ICC 17249 & Cicer microphyllum Benth. & 2.7 & 74.0 & 1.726 & 0.18 \\
\hline Annigeri & Cicer arietinum $\mathrm{L}$. & 5.8 & 88.0 & 5.448 & 2.63 \\
\hline ICC 506 EB & Cicer arietinum $\mathrm{L}$. & 4.8 & 94.0 & 4.686 & 3.75 \\
\hline ICCC 37 & Cicer arietinum $\mathrm{L}$. & 7.2 & 86.0 & 6.602 & 3.40 \\
\hline Mean & & 4.6 & 83.0 & 2.324 & 1.0 \\
\hline SE & & \pm 0.51 & \pm 6.88 & \pm 0.38 & - \\
\hline
\end{tabular}

*Damage rating $(1=<10 \%$ leaf area damaged, and $9=>80 \%$ leaf area damaged $)$.

the moderately resistant check, and $6.602 \mathrm{mg}$ on ICCC 37 - the susceptible check. Larval weights were $<1.5 \mathrm{mg}$ when the larvae were reared on the leaves of six accessions belonging to C. microphyllum (ICC 17146, ICC 17234, ICC 17236, ICC 17240, ICC 17243, and ICC 17248). There was a significant reduction in both leaf feeding and larval weight gain when the larvae were fed on the leaves of C. microphyllum accessions ICC 17146, ICC 17236, ICC 17240, ICC 17248 and ICC 17249. Thus, some of the accessions of perennial wild relatives of chickpea not only suffered low leaf damage, but also showed significant negative effects on larval survival and weight gain.

Relative resistance index based on leaf feeding, larval survival, and larval weight indicated that accessions belonging to wild relatives were less suitable for feeding, growth and development of $H$. armigera larvae. Cicer microphyllum accessions ICC 17146, ICC 17236, ICC 17234, ICC 17240, ICC 17243, and ICC 17248 showed high levels of resistance (resistance index $<0.52$ ) to $H$. armigera as compared to the cultivated chickpea genotypes ICC 506 - the resistant check (resistance index 3.75 ) and ICCC 37 - the susceptible check (resistance index 6.602). Accessions of $C$. canariense and $C$. pungens were also resistant to $H$. armigera (resistance index 0.73 and 1.71, respectively).

Similarity matrix analysis based on leaf feeding, larval survival and larval weight under greenhouse conditions grouped the accessing into four hierarchical groups (coefficient 0.988) (Figure 1). Cicer pungens was grouped with $C$. microphyllum accessions ICC 17242, 17234, 17238, 17237, and 17245; while C. canariense accession ICC 17202 was grouped with C. microphyllum accessions ICC 17239, 17244, 17248, 17240, 17247, 17236, 17249, 17146, and 17235. The cultivated chickpea genotypes were placed in one group; while C. microphyllum accessions ICC 17243 was placed independently of other accessions of the same species. Principal component analysis based on leaf damage rating, larval survival, and weight gain placed the material into six groups (Figure 2). The cultivated chickpea genotypes Annigeri and ICCC 37, susceptible to $H$. armigera, were placed in one group; while the resistant check, ICC $506 \mathrm{~EB}$, was placed in a separate group. Cicer pungens accession ICC 17138 was grouped with C. microphyllum accessions, ICC 17234, 17237, 


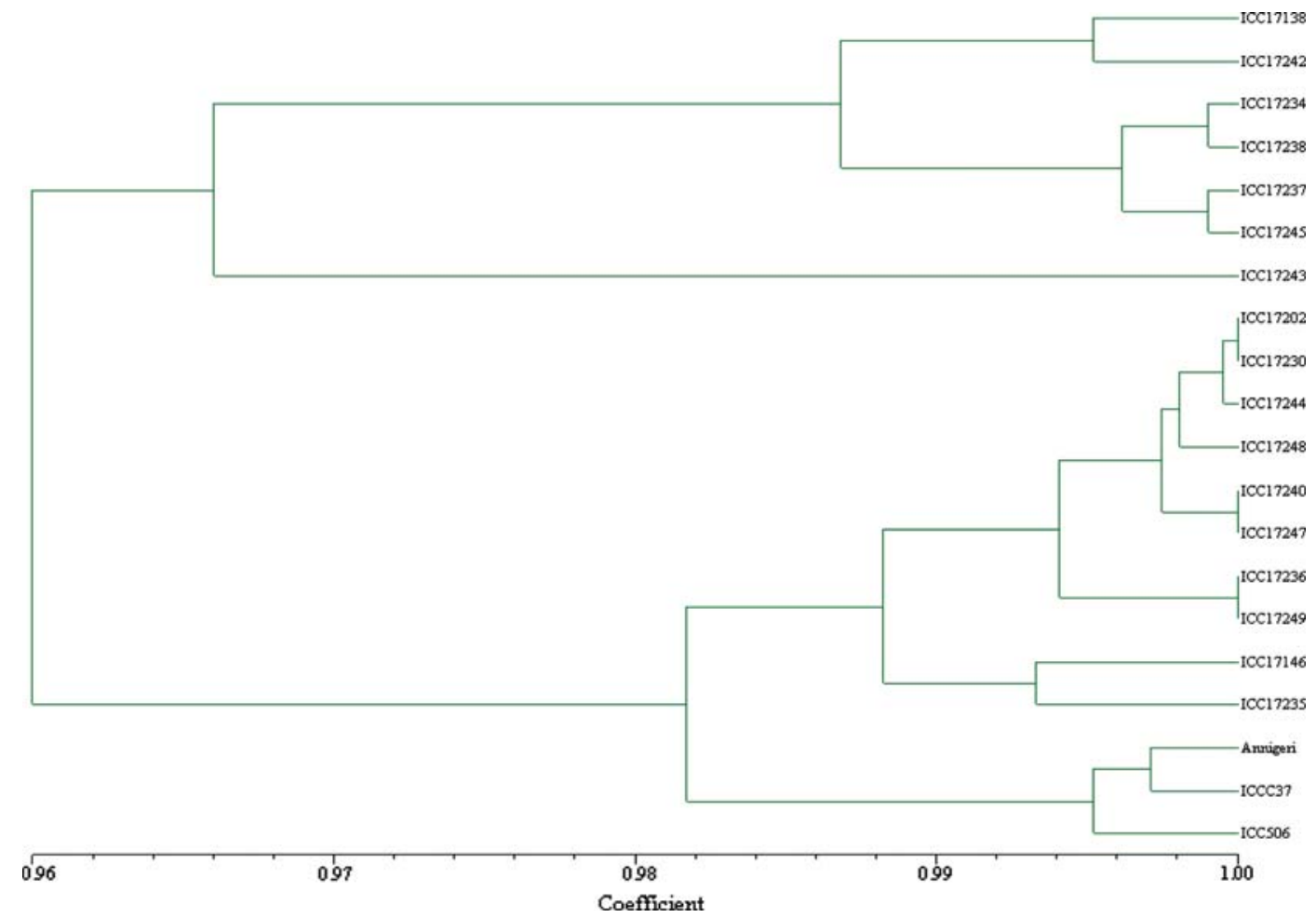

Figure 1. Dendrogram depicting genetic similarity between 17 accessions of perennial Cicer species and three cultivated chickpeas for their reaction to H. armigera . [C. pungens (ICC 17138), C. canariense (ICC 17202), C. microphyllum (ICC 17146, ICC 17230, ICC 17234, ICC 17235, ICC 17236, ICC 17237, ICC 17238, ICC 17240, ICC 17242, ICC 17243, ICC 17244, ICC 17245, ICC 17247, ICC 17248, and ICC 17249), and C. arietinum (Annigeri, ICC 506EB, and $20=$ ICCC 37)].

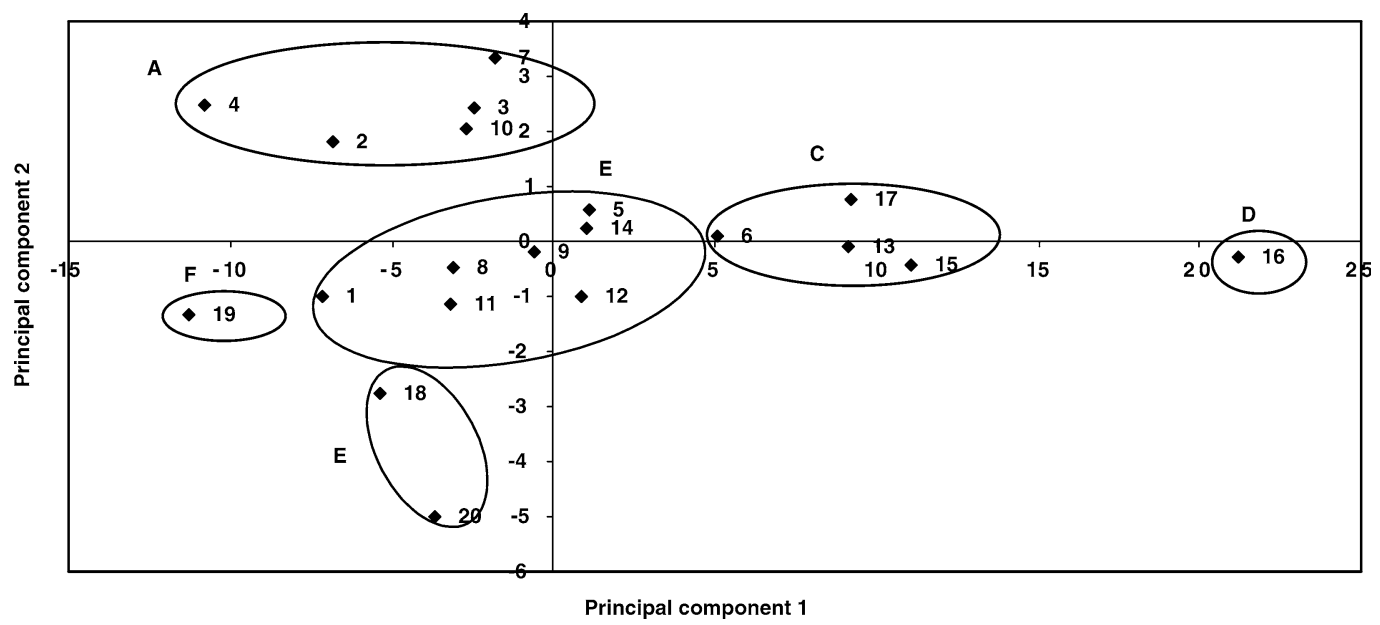

Figure 2. Principal component analysis of perennial wild relatives of chickpea based on $H$. armigera damage rating, larval survival, and larval weight $(1=$ ICC 17138, $2=$ ICC 17202, $3=$ ICC 17146, $4=$ ICC 17230, $5=$ ICC 17234, $6=$ ICC $17235,7=$ ICC 17236, $8=$ ICC 17237, $9=$ ICC 17238, $10=$ ICC 17240, $11=$ ICC 17242, $12=$ ICC 17243, $13=$ ICC 17244, $14=$ ICC 17245, $15=$ ICC 17247, $16=$ ICC 17248, and $17=$ ICC 17249, $18=$ Annigeri, $19=$ ICC 506EB, and $20=$ ICCC 37). 
17238, 17242, 17243, and 17245; while C. canariense (ICC 17202) was grouped with C. microphyllum accessions ICC 17146, 17230, and 17236. Accession ICC 17248 was placed distantly from the other C. microphyllum accessions.

Relative susceptibility of perennial wild relatives of chickpea to $\mathrm{H}$. armigera under multi-choice conditions in the field

The Helicoverpa armigera damage from natural infestation to cultivated chickpea genotypes (Annigeri, ICCC 37, and ICC 506) at Kothi was very high, and had a leaf and pod damage rating of $8-9(>70 \%$ of the leaf area and/or pods damaged) (Table 2). Some of the accessions showed regeneration after the first shoot dried up (ICC 17244, ICC 17248, ICC 17231, and ICC 17148). However, none of them flowered to produce pods. Ten accessions belonging to $C$. microphyllum, 1 to $C$. canariense, and 1 to $C$. macracanthum suffered a damage rating of $<2.0$ compared to 4.0 in $C$. judaicum (an annual species) and 8.5-9.0 in the cultivated chickpeas.

\section{Discussion}

There were significant differences in leaf feeding, larval survival, and larval weight when the neonate larvae of $H$. armigera were released on the detached leaves from the perennial wild relatives of chickpea. There was a significant reduction in both leaf feeding and larval weights when the larvae were fed on the leaves of $C$. microphyllum accessions ICC 17146, 17236, 17240, and 17248. Relative resistance index based on leaf feeding, larval survival, and larval weight indicated that C. microphyllum accessions ICC 17146, 17236, 17240,17243 , and 17248 were highly resistant to $H$. armigera as compared to the cultivated chickpea. Similarity matrix and principal component analysis indicated that there was considerable diversity among the perennial wild relatives of chickpea for their reaction to $H$. armigera.

The $H$. armigera damage on cultivated chickpea at a height of $2500 \mathrm{~m}$ near Manali, India, was very high. ICC 506EB, which has been found to be most resistant to $H$. armigera in field and laboratory tests earlier (Lateef 1985; Lateef and Sachan 1990), showed a susceptible reaction at this location. Acid exudates such as malic acid and oxalic

Table 2. Evaluation of perennial wild relatives of chickpea for resistance to Helicoverpa armigera under multi-choice conditions in the field (Manali, Himachal Pradesh, 2003).

\begin{tabular}{lllll}
\hline Accession & Species & Plant survival 180 DAE & Regeneration 180 DAE & Damage rating* \\
\hline ICC 17229 & C. microphyllum Benth. & $\mathrm{x}$ & $\mathrm{x}$ & 1.0 \\
ICC 17237 & C. microphyllum Benth. & $\mathrm{x}$ & $\mathrm{x}$ & 1.0 \\
ICC 17238 & C. microphyllum Benth. & $\mathrm{x}$ & $\mathrm{x}$ & 2.0 \\
ICC 17239 & C. microphyllum Benth. & $\mathrm{x}$ & $\mathrm{x}$ & 2.0 \\
ICC 17243 & C. microphyllum Benth. & $\mathrm{x}$ & $\sqrt{ }$ & 1.5 \\
ICC 17244 & C. microphyllum Benth. & $\sqrt{ }$ & $\mathrm{x}$ & 1.0 \\
ICC 17247 & C. microphyllum Benth. & $\mathrm{x}$ & $\sqrt{ }$ & 1.0 \\
ICC 17248 & C. microphyllum Benth. & $\sqrt{ }$ & $\mathrm{x}$ & 2.0 \\
ICC 17249 & C. microphyllum Benth. & $\mathrm{x}$ & $\mathrm{x}$ & 2.0 \\
ICC 17230 & C. microphyllum Benth. & $\sqrt{ }$ & $\sqrt{ }$ & 4.0 \\
ICC 17231 & C. microphyllum Benth. & $\sqrt{ }$ & $\mathrm{x}$ & 1.0 \\
ICC 17138 & C. pungens Benth. & $\mathrm{x}$ & $\mathrm{x}$ & 3.0 \\
ICC 17202 & C. canariense Santos Guerra et Lewis & $\sqrt{ }$ & $\mathrm{x}$ & 1.0 \\
ICC 17216 & C. macranthum M. Pop. & $\mathrm{x}$ & $\sqrt{ }$ & 2.0 \\
ICC 17148 & C. judaicum Boiss. & $\sqrt{ }$ & - & 4.0 \\
ICCC 37 & C. arietinum L. & - & - & 9.0 \\
ANNIGERI & C. arietinum L. & - & - & 8.5 \\
ICC $506 E B$ & C. arietinum L. & - & - & 9.0 \\
Mean & & - & - & 3.1 \\
SE & & -1 & \pm 0.7
\end{tabular}

*DR - Damage rating $(1=<10 \%$ leaf area damaged, and $9=>80 \%$ leaf area damaged $)$.

DAE - Days after seedling emergence. $\mathrm{x}$ - No plant survival or regeneration.

$\sqrt{ }$ - Plants survived and regenerated at 180 days after seedling emergence. 
acid on the leaves are responsible for chickpea resistance to $H$. armigera (Cowgill and Lateef 1996). Since there is dew formation and occasional rainfall during the summer season in this region, these chemicals might have been washed from leaf surface, and thus resulting in greater damage in ICC 506.

All the accessions showing resistance to $H$. armigera in the detached leaf assay also showed lower susceptibility under field conditions. Cicer microphyllum was observed growing in its natural habitat in mid-July at the Regional Research Station, Himachal Pradesh Agricultural University, Kukumseri, Udaipur $(50 \mathrm{~km}$ west of Keylong), and on the sides of rivulets feeding the river Chenab (near Trilokinath at a height of 2500-3000 m above mean seas level). There was no insect damage in these plants at the podding stage. In future, it may be possible to grow the perennial Cicer germplasm in this area to multiply the seed, and possibly test them at the fruiting stage for resistance to $H$. armigera. Cicer canariense flowers and sets seed outside the range of its distribution, and can be used for genetic improvement of chickpea (Pundir et al. 1993).

Accessions belonging to annual wild relatives of chickpea have earlier been evaluated for resistance to insect pests and diseases. Accessions belonging to $C$. bijugum K. H. Rech. C. pinnatifidum Jaub. et Sp., and C. echinospermum P. H. Davis have shown resistance to H. armigera (Kaur et al. 1999; Sharma et al. 2002), leaf miner (Liriomyza cicerina Rondani) and bruchids (Callosobruchus chinensis L.) (Singh et al. 1990, 1997, 1998). There are no reports on the hybridization of perennial wild relatives with the cultivated chickpea. Development of tissue culture techniques might open up new opportunities to access genes from incompatible wild species, including the perennial species, because most of the genes for resistance to abiotic and biotic stresses has been found in the tertiary gene pool (Muehlbauer 1987). High levels of genetic resistance to $H$. armigera found in perennial wild relatives of chickpea seem to have different mechanisms of resistance. Identification and isolation of lectin and protein inhibitor genes from the wild species offers another opportunity for their deployment through transgenic plants. Development of techniques to overcome compatibility barriers and chromosome engineering may lead to increased utilization of wild relatives of chickpea for resistance to $H$. armigera.

\section{Acknowledgements}

We thank the staff of entomology for help in the experiments, Dr H.D. Upadhayaya for providing the seeds of the perennial species from the ICRISAT genebank, and Dr P.M. Gaur for reviewing the manuscript. Mr Khoob Ram assisted with managing the crop at Manali, Dr J.R. Thakur, Regional Research Station Bajaura cooperated in undertaking these studies, and the scientists at the Regional Research Station, Kukumseri helped in finding the wild relatives of chickpea in their natural habitat. We also thank the Grains Research and Development Corporation (GRDC), Australia, for funding this research.

\section{References}

Armes N.J., Jadhav D.R. and DeSouza K.R. 1996. A survey of insecticide resistance in Helicoverpa armigera in the Indian subcontinent. Bull. Entomol. Res. 86: 499-514.

Chandel K.P.S. 1984. A note on occurrence of wild Cicer microphyllum Benth. and its nutrient status. Int. Chickpea Newslett. 10: 4-5.

Cowgill S.E. and Lateef S.S. 1996. Identification of antibiotic and antixenotic resistance to Helicoverpa armigera (Lepidoptera: Noctuidae) in chickpea. J. Econ. Entomol. 89: 224-229.

ICRISAT(International Crops Research Institute for the SemiArid Tropics). 1992. The Medium Term Plan. ICRISAT, Patancheru, A.P. 502 324, India.

Kaur S., Chhabra K.S. and Arora B.S. 1999. Incidence of Helicoverpa armigera (Hübner) on wild and cultivated species of chickpea. Int. Chickpea Pigeonpea Newslett. 6: 18-19.

Kranthi K.R., Jadhav D.R., Kranthi S., Wanjari R.R., Ali S.S. and Russel D.A. 2002. Insecticide resistance in five major insect pests of cotton in India. Crop Protect. 21: 449-460.

Ladizinsky G. and Adler A. 1976. Genetic relationships among the annual species of Cicer L. Theor. Appl. Genet. 48: 197-203.

Lateef S.S. 1985. Gram pod borer [Heliothis armigera (Hübn.)] resistance in chickpea. Agric. Ecosyst. Environ. 14: 95-102.

Lateef S.S. and Sachan J.N. 1990. Host plant resistance to Helicoverpa armigera (Hübn.) in different agro-economical conditions. In: Chickpea in Ninetees: Proceedings of the Second International Workshop on Chickpea, 4-8 Dec 1989. International Crops Research Institute for the Semi-Arid Tropics, Patancheru, Andhra Pradesh, India, pp. 181-189.

Muehlbauer F.J. 1987. Use of wild species as a source of resistance in cool-season food legume crops. In: Singh K.B. and Saxena M.C. (eds.), Breeding for Stress Tolerance in Cool-Season Food Legumes. John Wiley and Sons, UK. 
Olsen K.M. and Daly J.C. 2000. Plant-toxin interactions in transgenic Bt cotton and their effect on mortality of Helicoverpa armigera (Lepidoptera: Noctuidae). J. Econ. Entomol. 93: 1293-1299.

Pundir R.P.S., Mengesha M.H. and Reddy G.V. 1993. Morphology and cytology of Cicer canariense, a wild relative of chickpea. Euphytica 69: 73-75.

Sharma H.C. 2001. Cotton Bollworm/Legume Pod Borer, Helicoverpa armigera (Hübner) (Noctuidae: Lepidoptera): Biology and Management. Crop Protection Compendium. Commonwealth Agricultural Bureau International Oxon, UK. 72 pp.

Sharma H.C., Mann K., Kashyap S.L., Pampapathy G. and Ridsdill-Smith J. 2002. Identification of Helicoverpa resistance in wild species of chickpeas. In: 12th Australian Plant Breeding Conference, 15-20 Sept 2002, Perth, Western Australia, Australia.

Sharma H.C., Stevenson P.C., Simmonds M.S.J. and Green P.W.C. 2001. Identification of Helicoverpa armigera (Hübner) feeding stimulants and the location of their production on the pod-surface of pigeonpea [Cajanus cajan (L.) Millsp.].
Final Technical Report. International Crops Research Institute for the Semi-Arid Tropics (ICRISAT), Patancheru, Andhra Pradesh, India, $85 \mathrm{pp}$.

Singh K.B., Malhotra R.S. and Saxena M.C. 1990. Sources for tolerance to cold in Cicer species. Crop Sci. 30: 1136-1138.

Singh K.B. and Ocampo B. 1993. Interspecific hybridization in annual Cicer species. J. Genet. Breed. 47: 199-204.

Singh K.B. and Ocampo B. 1997. Exploitation of wild Cicer species for yield improvement in chickpea. Theor. Appl. Genet. 95: 418-423.

Singh K.B., Ocampo B. and Robertson L.D. 1998. Diversity for abiotic and biotic stress resistance in the wild annual Cicer species. Genet. Resour. Crop Evol. 45: 9-17.

Singh K.B., Weigand S. and Saxena M.C. 1997. Registration of ILWC 39 and ILWC 181: Cicer echinospermum germplasm lines with resistance to Callosobruchus chinensis (L.). Crop Sci. 37: 634.

Stalker H.T. 1980. Utilization of wild species for crop improvement. Adv. Agron. 23: 111-147. 